\title{
Mepolizumab as a steroid-sparing treatment option in a patient with eosinophilic granulomatosis with polyangiitis
}

\author{
Mepolizumabe como terapêutica poupadora de esteroides num paciente \\ com granulomatose eosinofílica com poliangiite
}

\author{
Ana Rita Presa ${ }^{1}$, Cristina Lara Valente ${ }^{1}$, Maria João Sousa ${ }^{1}$, Dorinda Inês Lopes ${ }^{1}$
}

\begin{abstract}
Granulomatose eosinofílica com poliangiite (EGPA) é uma doença multissistêmica caracterizada por asma, eosinofilia no sangue periférico e sinais de vasculite. Os corticoides são considerados a base do tratamento, no entanto, a maioria dos pacientes permanece dependente deste tratamento com os seus efeitos adversos associados. Relatamos o caso de um paciente com granulomatose eosinofílica dependente de esteroides com poliangiite (EGPA) tratado com sucesso com mepolizumabe. Um homem de 36 anos apresentou rinite persistente, dispneia, sibilos e tosse seca mal controlada com terapia inalada. Observou-se eosinofilia no sangue periférico e no lavado broncoalveolar. Os achados histológicos da mucosa nasal revelaram microabscessos eosinofílicos e vasculite sem granulomas compatíveis com o diagnóstico de EGPA. Após o início da prednisolona oral diária (PSL), os sintomas e a eosinofilia melhoraram, mas surgiram efeitos adversos. As tentativas de redução gradual da PSL resultaram no agravamento dos sintomas. Iniciou mepolizumabe $300 \mathrm{mg}$ mensalmente, com melhora clínica e remissão sustentada da doença, o que permitiu reduzir a necessidade de PSL. Apresentamos um EGPA dependente de esteroides muito incapacitante. O mepolizumab foi capaz de diminuir o PSL mantendo o controle sintomático sustentado.
\end{abstract}

Descritores: Granulomatose eosinofílica com poliangiite, interleucina-5, mepolizumabe.

\section{Introduction}

Eosinophilic granulomatosis with polyangiitis (EGPA), known as Churg-Strauss syndrome until 2012, is currently recognized as one form of antineutrophil cytoplasmic antibody (ANCA)-

\section{RESUMO}

Eosinophilic granulomatosis with polyangiitis (EGPA) is a multisystem disorder characterized by asthma, peripheral blood eosinophilia, and signs of vasculitis. Glucocorticoids are considered the cornerstone of treatment, but most patients remain steroid-dependent and carry a significant burden of adverse effects. We report a case of a patient with steroid-dependent EGPA successfully treated with mepolizumab. A 36-year-old man presented with persistent rhinitis, dyspnea, wheezing, and dry cough poorly controlled with inhaled therapy. Eosinophilia in peripheral blood and bronchoalveolar lavage fluid was seen. Histological findings from nasal mucosa revealed eosinophilic microabscesses and vasculitis without granulomas compatible with EGPA diagnosis. After daily oral prednisolone (PSL) was started, symptoms and eosinophilia improved, but adverse effects emerged. Attempts at tapering off PSL resulted in worsening of symptoms. He started mepolizumab 300 mg monthly, with clinical improvement and sustained disease remission, which allowed reducing the need for PSL. We present a very disabling steroiddependent EGPA. Mepolizumab was able to taper off PSL while maintaining symptomatic control.

Keywords: Eosinophilic granulomatosis with polyangiitis, interleukin-5, mepolizumab.

associated vasculitis (AAV). It is characterized by eosinophil-rich granulomatous inflammation and vasculitis affecting small- to medium-sized vessels, associated with asthma and eosinophilia. ${ }^{1}$ The precise

1. Centro Hospitalar Vila Nova de Gaia/Espinho, Departamento de Alergologia - Vila Nova de Gaia, Porto, Portugal.

Submitted: 03/22/2021, accepted: 05/01/2021.

Arq Asma Alerg Imunol. 2021;5(3):298-301.

http://dx.doi.org/10.5935/2526-5393.20210047 
role of eosinophils remains uncertain, but evidence of eosinophilic tissue infiltration and eosinophilic granulomatous inflammation suggests that they are key cells in EGPA pathogenesis.. ${ }^{2}$ Glucocorticoids are considered the cornerstone of treatment for patients with EGPA as they reduce blood and tissue eosinophil counts. ${ }^{3}$ However, most of these patients remain steroid-dependent despite the use of immunosuppressant treatment and carry a significant burden of adverse effects. ${ }^{4}$ Mepolizumab, a humanized monoclonal antibody that targets interleukin-5 (IL-5), is indicated for treatment of severe eosinophilic asthma and, in 2017, obtained United States Food and Drug Administration (FDA) approval for EGPA. ${ }^{5}$

We report a case of a Caucasian man with steroid-dependent EGPA successfully treated with mepolizumab.

\section{Case description}

A 36-year-old man presented with a history of severe and persistent rhinitis and dyspnea, wheezing, and dry cough almost every day since acute respiratory infection occurred two months earlier. He was medicated with a maximum dose of inhaled corticosteroid (fluticasone propionate) and beta-agonist (salmeterol) and then referred to our allergy department.

In the first consultation, after one month, he reported partial improvement of symptoms and started diagnostic workup. Skin tests for perennial or seasonal inhalant allergens were negative. Although he had done deworming once a year in recent years, peripheral blood eosinophilia $(1210 / \mu \mathrm{L}, 14 \%$ of white blood cell count) was noted. Therefore, he underwent another deworming treatment with albendazole that led to a reduction in eosinophil count $(530 / \mu \mathrm{L}, 8 \%$ of white blood cell count). Fractional exhaled nitric oxide (FeNO) and pulmonary function test (PFT) results were normal.

One year later, he had an episode of acute exacerbation of respiratory symptoms 30 minutes after treatment with diclofenac injection. He underwent a challenge test with diclofenac revealing a positive reaction (anaphylaxis) and, later, he mentioned exacerbation of respiratory symptoms also with ibuprofen. Diagnosis of nonsteroidal anti-inflammatory drug-exacerbated respiratory disease (NERD) was made, and etoricoxib was proven safe after a drug provocation test in our department.
Chest computed tomography showed groundglass opacities in the right lower lobe and cylindrical bronchiectasis in the lower lobes. Bronchoalveolar lavage revealed marked eosinophilia (68\%). Antinuclear antibodies and ANCA levels were negative.

This patient was a security guard spending 10 hours a day in an armored van. He reported worsening respiratory symptoms due to car air conditioning, which led him to stop working for weeks to months. Also, there were other flare-ups related to respiratory infections and others with no specific identified trigger which required antibiotics (amoxicillin/clavulanic acid, moxifloxacin, clarithromycin), inhaled long-acting muscarinic receptor antagonist (LAMA), and systemic corticosteroid therapy (average dose, $70 \mathrm{mg} /$ day of prednisolone [PSL] for 3-5 days). In addition, he attended the emergency department twice over one week complaining of abdominal pain and diarrhea. Blood tests demonstrated worsening eosinophilia (1220/ $\mathrm{LL}$ and $2750 / \mu \mathrm{L})$. Abdominal ultrasound showed a thickened wall of terminal ileum compatible with an inflammatory process. He was treated with antibiotics (ciprofloxacin and metronidazole), with resolution of symptoms.

Almost three years after the first appointment, because of poorly controlled respiratory symptoms, he started taking $40 \mathrm{mg}$ of oral PSL daily $(0.5 \mathrm{mg} / \mathrm{kg} /$ day). In addition to the previously mentioned symptoms, he also complained of persistent obstructive rhinitis and anosmia. He underwent a paranasal sinus computed tomography scan, which revealed nasal septal deviation, bilateral polyps, and pansinusitis. Then he underwent polypectomy, endoscopic ethmoidectomy, and bilateral maxillary antrostomy, with partial improvement of nasal symptoms. Histological findings obtained from nasal mucosa revealed eosinophilic microabscesses and eosinophilic vasculitis without granulomas. Based on these findings, a definitive diagnosis of EGPA was made. Electrocardiogram, echocardiogram, and cardiac magnetic resonance imaging excluded cardiac involvement. The patient also complained of hand paresthesias and difficulty gripping. Normal electromyogram and the absence of other neurological signs excluded neuropathy.

After daily oral PSL was implemented, the symptoms and eosinophilia improved, and the patient was able to reduce inhaled corticosteroid therapy and withdraw LAMA. However, less than one month later, he developed side effects of corticosteroids (facial edema, acne, weight gain, increased appetite, psychosis, and anxiety). Several attempts at tapering 
off PSL were made to use the lowest dose necessary to control symptoms, but all of them led to worsening respiratory symptoms requiring a further dose increase.

For those reasons, he started mepolizumab $300 \mathrm{mg}$ monthly. The patient showed clinical improvement and started tapering off prednisolone. Currently, he has sustained clinical symptomatic control and is no longer under systemic corticosteroid therapy.

\section{Discussion}

EGPA is a systemic necrotizing vasculitis characterized by blood and tissue eosinophilia. Typically, it comprises three phases (prodromal, eosinophilic, and vasculitic), each characterized by a group of manifestations that can overlap. ${ }^{6}$ Glucocorticoids are the mainstay of EGPA treatment; however, given its side effects and based on the increasing knowledge on the pathophysiology of EGPA, alternative approaches have emerged. ${ }^{7}$ The role of eosinophils in EGPA pathogenesis is not fully understood yet, but, given their cytotoxic properties and evidence of eosinophilic tissue infiltration and eosinophilic granulomatous inflammation, they potentially play a prominent role in EGPA, whether acting as effector or immunoregulatory cells. ${ }^{2}$ IL-5 mediates proliferation, maturation, and activation of eosinophils, and its levels are increased in patients with EGPA and might correlate with disease activity. 8 Therefore, inhibition of IL-5 has become a very reasonable therapeutic approach for managing EGPA.

Mepolizumab is a humanized monoclonal $\mathrm{N}$-glycosylated $\lg \mathrm{G} 1 / \mathrm{k}$ antibody that binds to the $\alpha$-chain of IL-5, thus preventing its association with the $\alpha$-subunit of the IL-5 receptor on the surface of eosinophils. It has been tested in several diseases, including severe eosinophilic asthma and others that share similar pathogenic mechanisms. ${ }^{9}$ The efficacy of mepolizumab was investigated as an add-on therapy in patients with refractory EGPA. Mepolizumab was associated with more time in remission and lower frequency of relapse compared with placebo, which allowed the reduction of steroid use. ${ }^{4}$ These results led to the approval of mepolizumab in adult patients with EGPA by the FDA in 2017, at a dose of 300 mg administered by subcutaneous injection every 4 weeks. ${ }^{10}$ According to a recent systematic review, mepolizumab is efficacious and safe for use in patients with EGPA. ${ }^{11}$
In this report, we present a very disabling case of EGPA refractory to high-dose inhaled therapy, leading to several visits to the emergency department and the need to take weeks off due to worsening symptoms at the workplace. It is noteworthy that diagnosis was not obvious, lying between chronic eosinophilic pneumonia and EGPA because of the absence of detectable ANCA and extrapulmonary involvement. Histological findings obtained from nasal mucosa that revealed eosinophilic microabscesses and eosinophilic vasculitis enabled the definitive diagnosis of EGPA. In retrospect, we also consider that gastrointestinal symptoms that led the patient to the emergency department in association with increased eosinophil count may correspond to a gastrointestinal flare of EGPA. This patient also had NERD, a feature observed in other EGPA patients. ${ }^{12}$

Remission was achieved with high-dose oral PSL therapy, but the disease relapsed in each attempt at tapering corticosteroid, and, less than a month later, the patient started to develop collateral effects. Finally, treatment with mepolizumab led to a sustained clinical improvement, and, until now, he has been able to discontinue PSL treatment.

In conclusion, we warn that differential diagnosis of severe asthma can be challenging. It is important to make an accurate diagnosis to provide the most appropriate treatment with the lowest risk for the patient.

\section{References}

1. Jennette JC, Falk RJ, Bacon PA, Basu N, Cid MC, Ferrario F, et al. 2012 revised International Chapel Hill Consensus Conference Nomenclature of Vasculitides. Arthritis Rheum. 2013;65:1e11.

2. Gioffredi A, Maritati F, Oliva E, Buzio C. Eosinophilic granulomatosis with polyangiitis: an overview. Front Immunol. 2014;5:549. doi: 10.3389/fimmu.2014.00549.

3. Fulkerson PC, Rothenberg ME. Targeting eosinophils in allergy, inflammation and beyond. Nat Rev Drug Discov.2013;12(2):117-29. doi: $10.1038 / \mathrm{nrd} 3838$.

4. Wechsler ME, Akuthota P, Jayne D, Khoury P, Klion A, Langford $\mathrm{CA}$, et al. Mepolizumab or placebo for eosinophilic granulomatosis with polyangiitis. N Engl J Med. 2017;376(20):1921-32.

5. Wu EY, Hernandez ML, Jennette JC, Falk RJ. Eosinophilic Granulomatosis with Polyangiitis: Clinical Pathology Conference and Review. J Allergy Clin Immunol Pract. 2018;6(5):1496-504. doi: 10.1016/j.jaip.2018.07.001.

6. Trivioli G, Terrier B, Vaglio A. Eosinophilic granulomatosis with polyangiitis: understanding the disease and its management. Rheumatology (Oxford). 2020;59(Suppl 3):iii84-iii94. doi: 10.1093/ rheumatology/kez570.

7. Carrillo-Martin I, Abril A, Donaldson AM, Gonzalez-Estrada A. An alternative approach against eosinophils for the treatment of eosinophilic granulomatosis with polyangiitis. J Allergy Clin Immunol Pract. 2020 Jun;8(6):2079-80. doi: 10.1016/j.jaip.2020.01.037. 
8. Hellmich B, Csernok E, Gross WL. Proinflammatory cytokines and autoimmunity in Churg-Strauss syndrome. Ann NY Acad Sci. 2005;1051:121-31. doi: 10.1196/annals.1361.053.

9. Bagnasco D, Ferrando M, Varricchi G, Puggioni F, Passalacqua G, Canonica GW. Anti-Interleukin 5 (IL-5) and IL-5Ra Biological drugs: efficacy, safety, and future perspectives in severe eosinophilic asthma. Front Med (Lausanne). 2017;4:135. doi:10.3389/ fmed.2017.00135.

10. Faverio P, Bonaiti G, Bini F, Vaghi A, Pesci A. Mepolizumab as the first targeted treatment for eosinophilic granulomatosis with polyangiitis: a review of current evidence and potential place in therapy. Ther Clin Risk Manag. 2018;14:2385-96. doi: 10.2147/ TCRM.S159949.

11. Pradhan RR, Nepal G, Mandal S. Safety and efficacy of mepolizumab in patients with eosinophilic granulomatosis with polyangiitis. Pulm Med. 2019;2019:4376380. doi:10.1155/2019/4376380.
12. Yılmaz Í, Tutar N, Simsek ZÖ, Oymak FS, Gülmez Í. Clinical and serological features of eosinophilic and vasculitic phases of eosinophilic granulomatosis with poliangiitis: a case series of 15 patients. Turk Thorac J. 2017;18(3):72-7. doi:10.5152/ TurkThoracJ.

No conflicts of interest declared concerning the publication of this article.

Corresponding author:

Ana Rita Presa

E-mail: aritapresa@gmail.com 